\title{
Ciência no desterro: a saga de Ramón Carrillo em Belém, estado do Pará, Brasil
}

\author{
Science in the exile: the saga of Ramón Carrillo in Belém, Pará State, Brazil \\ José Maria de Castro Abreu Junior', Aristoteles Guilliod de Miranda \\ ' Universidade Federal do Pará, Instituto Histórico e Geográfico do Pará, Belém, Pará, Brasil
}

\section{RESUMO}

Ramón Carrillo (1906-1956), importante médico argentino, professor, cientista, sanitarista e Ministro da Saúde, durante o governo Perón, na Argentina, trouxe uma nova visão de saúde pública para a América Latina. Com a queda do peronismo, em 1955, exilou-se na cidade de Belém, estado do Pará, Brasil, onde viveu por cerca de um ano até o seu falecimento. Este artigo buscou mostrar quais atividades desenvolveu na capital paraense, considerando-se que algumas de suas biografias pouco tratam dessa etapa de sua vida.

Palavras-chave: História da Medicina; Médicos; Biografia.

\section{ABSTRACT}

Ramón Carrillo (1906-1956), an important Argentine physician, professor, scientist, health scientist and Minister of Health under the Perón administration, in Argentina, brought a new vision of public health for Latin America. With the fall of the Peronism, in 1955, Carrillo was exiled in the city of Belém, Pará State, Brazil, where lived for about a year until his death. This article shows what activities he developed in the capital of Pará, considering that some of his biographies do not report properly this stage of his life.

Keywords: History of Medicine; Physicians; Biography.

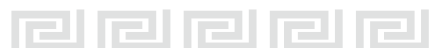

\section{PARTINDO DE UMA ANTI-HISTÓRIA}

Uma notícia veiculada na grande imprensa pode ter o papel de desafiar o faro de pesquisadores. Quando os fatos são expostos de modo contraditório, a questão se torna ainda mais instigante. Certa vez, um jornal paraense divulgou que seria lançado um livro sobre a vida do médico argentino Ramón Carrillo, que "[...] residiu em Belém, onde participou da criação da Faculdade de Medicina do Pará [... $]^{11]}$.

Embora o passado seja um período imutável, seu conhecimento é matéria em progresso, que incessantemente se transforma e se aperfeiçoa ${ }^{2}$. Conhecendo bem as origens da Faculdade de Medicina mais antiga do Norte e Nordeste (excetuando-se, claro, a da Bahia), podemos afirmar que, na época de sua fundação, ocorrida em 1919, não há, nas listas dos componentes iniciais, algum médico nascido na Argentina. $\bigcirc$ mais esdrúxulo foi constatar que Ramón Carrillo tinha 13 anos de idade no ano em que a Faculdade de Medicina e Cirurgia do Pará foi fundada. Essa anti-história bizarra com um suposto pré-adolescente genial, vindo de outro país e fundando uma escola médica no extremo norte, deixou-nos muito curiosos para conhecer quem era verdadeiramente aquele personagem. Não seria a primeira vez nem a última que os jornais de Belém publicariam notas descompromissadas com a história, seja da Medicina ou não. Mas a notícia desencontrada serviu para tomarmos conhecimento da existência de Ramón Carrillo.

\section{RAMÓN CARRILLO: POUCAS LINHAS PARA UM HOMEM MUITO GRANDE} y olvidemos al enfermo como una unidad biológica, psicológica y social, seremos simples zapateros remendones de la personalidad humana."

Ramón Carrillo ${ }^{3}$.

Dr. Carrillo tornou-se parte de nossos objetos de estudos, notadamente por sua obscura e, para nós, 
misteriosa permanência em Belém. Começamos lentamente a levantar dados sobre ele, sabendo que "[...] há, no fundo de toda pesquisa documentária, um resíduo de inopinado e, por conseguinte, de risco."2.

Filho primogênito do professor Ramón Carrillo e de Salomé Gomez, Carrillo nasceu em 7 de março de 1906, na cidade argentina de Santiago del Estero, tendo sido um destacado estudante das escolas locais. Aos 17 anos de idade, mudou-se para a capital, Buenos Aires, onde iniciou sua formação médica na Faculdade de Ciências Médicas da Universidade de Buenos Aires. No curso médico, foi estudante laureado, recebendo medalha de ouro pelo seu desempenho acadêmico e prêmio de melhor tese de doutoramento ao formar-se em 19294,5.

Influenciado por mestres locais, escolheu a neurocirurgia como especialidade, que na época estava ainda muito associada à neuroclínica, tendo produzido diversos trabalhos na área, como estudos sobre ventriculografia. Inquieto e estudando cerca de 18 h por dia, Carrillo (Figura 1) também tinha muito interesse em temas ligados à filosofia e à psiquiatria, conquistando a admiração do filósofo Keyserling por trabalhos como "A biologia no sistema filosófico de Keyserling ${ }^{114,5}$.

Com uma bolsa conseguida na Universidade de Buenos Aires, em 1930, partiu para aprimorar seus conhecimentos na Holanda, França e Alemanha, onde desenvolveu estudos sobre anatomia patológica do sistema nervoso central. Na Europa, descobriu a etiologia de um tipo de encefalite, posteriormente denominada "encefalite do tipo Carrillo", comum em mulheres norte-americanas, com cerca de 30.000 casos descritos, ao associá-la à ingestão de uma substância encontrada em uma bebida chamada "Gengibre da Jamaica"4,5.

Em 1933, regressou da Europa e tornou-se responsável pela organização do Laboratório de Neuropatologia do Instituto de Clínica Cirúrgica, dividindo o seu tempo entre a neurocirurgia e o laboratório6. Alguns anos depois, em maio de 1939, foi designado chefe do Serviço de Neurologia e Neurocirurgia do Hospital Militar Central ${ }^{4}$; e, por concurso, nomeado professor adjunto de Neurocirurgia da Faculdade de Ciências Médicas de Buenos Aires, em 19425. Naquele momento, já estava mais do que consagrado como pesquisador, com uma produção acadêmica extensa, fazendo parte de associações científicas de diversos países ${ }^{7}$.

Uma grande guinada na sua carreira de médico e pesquisador aconteceu em 1944, quando aderiu ao movimento peronista, após conhecer Juan Perón ${ }^{4,5}$, nascendo ali uma relação de respeito mútuo ${ }^{6}$, a ponto de Perón e Evita terem sido seus padrinhos de casamento $^{4}$, e Perón destacar, certa vez, que Carrillo havia sido seu único mestre ${ }^{6}$.

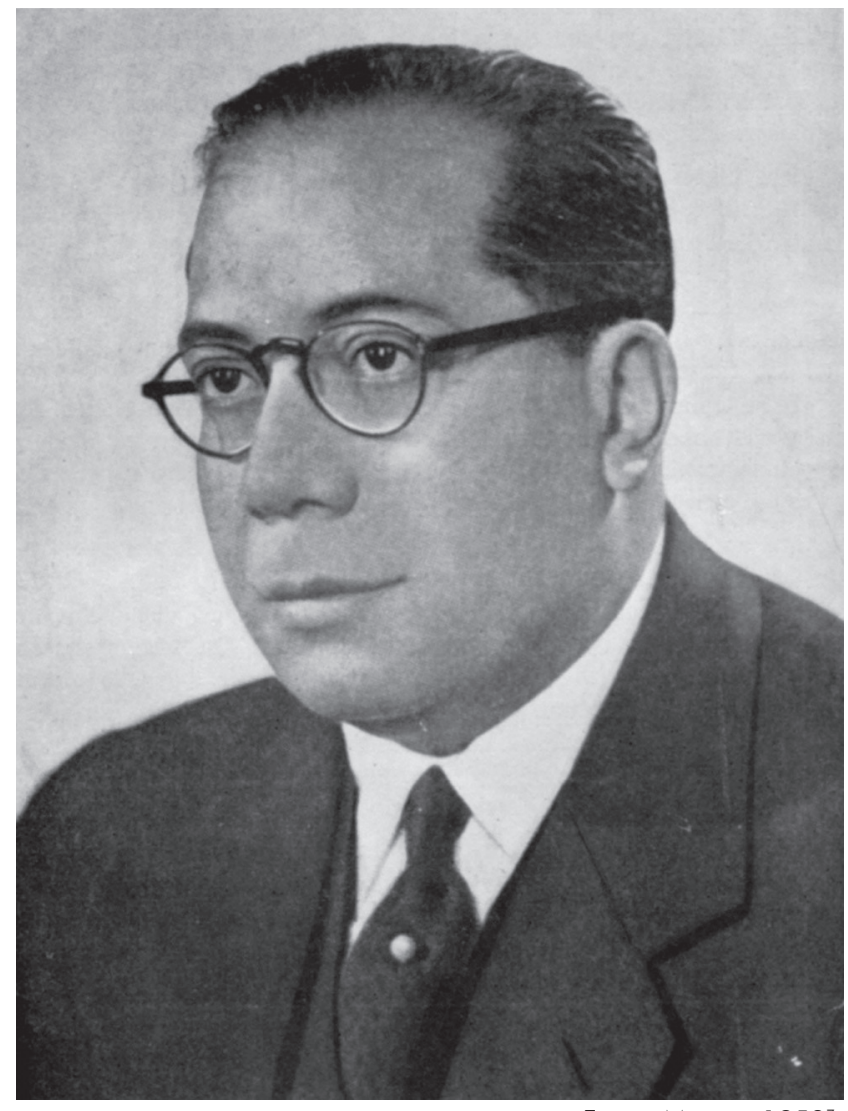

Fonte: Matera, $1958^{7}$

Figura 1 - Ramón Carrillo

Quando Perón assumiu a presidência da Argentina, em 1946, foi criado o cargo de Primeiro Ministro da Saúde especialmente para Ramón Carrillo. Até então, as questões sanitárias eram de responsabilidade do Departamento Nacional de Higiene ${ }^{4,5}$. Atuando com bastante autonomia, Carrillo transformou-se: de cientista, pesquisador e professor, figuras normalmente focadas em problemas específicos, passou também a ser um sanitarista capaz de estudar problemas muito amplos e complexos, como construção, organização e administração hospitalar, estudo das grandes endemias, combate às epidemias e difusão dos conceitos modernos de saúde pública ${ }^{5}$.

Em uma época em que a saúde pública estava ainda intimamente associada a ações filantrópicas realizadas por entidades que praticavam ações sociais, Carrillo planejou seu programa partindo de três diretrizes básicas:

$1^{\circ}$ - Todo homem tem direito igual à vida e à saúde.

$2^{\circ}$ - Não pode haver política sanitária sem política social.

$3^{\circ}$ - De nada servem as conquistas tecnológicas da Medicina se elas não podem chegar ao povo por meio de dispositivos adequados 5 .

Com o olhar do tempo presente, parece algo muito óbvio, mas essa era uma visão bem inovadora para o final da década de 1940. A título de comparação, essa forma de pensar a saúde só se estabeleceria legalmente no Brasil a partir da Constituição de 1988, e isso 
mais em termos filosóficos do que em uma realidade plenamente estabelecida.

Voltando para a Argentina e a gestão de Carrillo, não se teve aqui como objetivo esgotar suas ações como ministro ou explicar minúcias do seu projeto de saúde pública; tudo isso renderia um livro inteiro, afastando-nos do foco inicial, que é a figura de Ramón Carrillo em Belém. Basta dizer que, durante - seu período no Ministério, foram criados 230 estabelecimentos sanitários de internação, 50 institutos especializados, 3.000 dispensários e centros de saúde, duas fábricas de alta tecnologia sanitária, além de ter havido um aumento de 66.300 leitos disponíveis, em 1946, para 134.000 em $1954^{5}$.

Em termos de indicadores mais óbvios, que sempre são levantados quando se analisa saúde pública, a Argentina teve um decréscimo na mortalidade infantil, que era de 90/1.000 nascimentos, em 1940, para 56/1.000 nascimentos, em 1954, quando Carrillo deixou o Ministério ${ }^{4}$. Não é à toa que Carrillo é reconhecido hoje, em seu país, como "Fundador do Sanitarismo Nacional"5 ou "Pai da Medicina Preventiva"4.

Em meio a divergências políticas ${ }^{5}$ e alegando problemas de saúde, decorrentes de uma hipertensão arterial maligna que o afligia desde 1951, causando persistentes e intensas cefaleias, Carrillo pediu demissão do cargo de ministro em 1954. Pouco depois, ganhou uma bolsa do governo para estudar um antibiótico nos Estados Unidos ${ }^{6}$ e também buscar tratamento para a sua saúde que se deteriorava ${ }^{4}$.

Morando em Nova York, o ex-ministro se submeteu a um intenso tratamento, logrando algumas melhoras transitórias ${ }^{5}$. Em 1955, em meio a um momento conturbado da política argentina, o governo de Juan Perón cai, tendo o mesmo que buscar asilo no Paraguai. $\bigcirc$ novo governo, autoproclamado de "Revolução Libertadora", exigiu que fossem investigados todos os funcionários da "ditadura deposta". Carrillo teve sua prisão decretada ${ }^{8}$ e seus bens confiscados, sob a acusação de enriquecimento ilícito ${ }^{5}$.

Sem condições de voltar à Argentina, onde era considerado um criminoso, e sem recursos para se manter em Nova York, só lhe restava aceitar um emprego oferecido por um amigo americano, o senador Joseph McCarthy. Seria, dali em diante, médico na empresa de mineração Hanna Mining \& Company, que contava com uma filial brasileira, situada a $150 \mathrm{~km}$ da cidade de Belém, no estado do Pará ${ }^{4}$.

Era a última etapa da vida do ex-ministro.

\section{ABRINDO UM PARÊNTESE: ARMADILHAS DA "ILUSÃO BIOGRÁFICA"}

"A vida é uma história contada por um idiota, cheia de som e de fúria, sem sentido algum."

William Shakespeare em Macbeth, Cena V, Ato V.

Apresentamos, no item anterior, uma biografia clássica, de um típico herói nacional. De fato, as fontes usadas foram livros produzidos na esteira de uma série de comemorações pelo centenário do nascimento do ex-ministro, quando o governo argentino, em um momento francamente de revalorização dos ideais peronistas, decretou 2006 como o "Ano de homenagem a Ramón Carrillo". Um desses trabalhos foi inclusive escrito pelo seu irmão, Arthuro Carrillo.

Portanto, os estudos biográficos sobre nosso personagem não conseguem escapar de um viés político. Estar atento a isso é um dos desafios do pesquisador. Um personagem poderá ter aspectos realçados ou esquecidos, dependendo de quem escreve e para quem escreve. Os antiperonistas ressaltam que as biografias de Carrillo são laudatórias e construídas sem base em uma reflexão crítica, chegando até a afirmar que ele era simpatizante nazista9, um germanófilo, coisa que as biografias oficiais, sempre fazem questão de desmentir, afirmando que ele era neutro quando se referia a essas questões ${ }^{4,5}$. Sua idoneidade científica por vezes também é questionada, pois, segundo autores revisionistas, sua tese para titularidade na Faculdade de Ciências Médicas apresentaria trechos inteiros do livro clássico de anatomia de Testut, sem a devida citação. E a rede de hospitais, por ele criada, funcionava com base nas ideias eugênicas, objetivando, portanto, a purificação da raça? .

De fato, Ramón Carrillo teve uma formação alicerçada em escolas alemãs, e, nas décadas de 1930 e 1940, as teorias eugenistas eram bem aceitas na ciência médica mundial, tendo ampla penetração na América Latina. Mas a acusação atinge os limites da comicidade, quando lembramos que Carrillo, segundo alguns biógrafos, era negró ${ }^{\text {. }}$

Uma biografia é sempre algo complexo de se analisar se não tivermos em mente que muitas facetas da personalidade humana podem ser suprimidas por autores pelos mais diversos motivos. Para Bourdieu ${ }^{10}$, tratar a vida como uma história, isso é, como uma sequência coerente de relatos que apontam para certa direção, é aceitar uma ilusão retórica, uma representação comum de uma existência reforçada por tradições literárias.

que dizer então, no caso específico do nosso personagem, cujas cores vão sendo pintadas dependendo da orientação política lou seria melhor dizer da paixão política de quem o descreve)? Só nos resta buscar amparo em Cueto e Palmer ${ }^{11}$, pesquisadores que, livres de tensões partidárias, definem as ações de Carrillo como notáveis, mesmo não contando com o apoio de parte da elite médica argentina, que desprezava o governo Perón.

Por fim, independente de erros e acertos, atributos de qualquer ser humano, tanto peronistas como antiperonistas reconhecem o papel importante de Ramón Carrillo na saúde pública da Argentina. Não há quem questione, por exemplo, seu programa de erradicação da malária e o aumento da expectativa de vida de 61,7 anos para 66,5 durante a 
sua gestão ${ }^{9}$

É essa figura pública, indubitavelmente proeminente, que passou o último ano da sua vida em Belém. São suas relações estabelecidas com a Cidade e seus desdobramentos que queremos analisar, tendo em mente que "[...] a história consiste em dizer o que se passou e não em julgar $[\ldots]^{112}$.

\section{O RECOMEÇO EM BELÉM: MINA SEM "ELDORADO"}

"Ahora vivo en la mayor pobreza, mayor de la que nadie puede imaginar [...]"

Carrillo em carta ao amigo Ponzio Godoy .

Ramón Carrillo desembarcou em Belém com esposa e filhos em 6 de outubro de 1955, cidade distante $3.800 \mathrm{~km}$ de sua Santiago del Estero, ${ }^{4,13}$, e viveu na capital do Pará por cerca de um ano. Nesse ponto, encontramos o enfoque principal deste estudo: mostrar a vida do ex-ministro em Belém. Isso se torna necessário porque as obras sobre Carrillo pesquisadas apresentam um viés mistificador do que é a Cidade, carregando aquele exotismo sempre associado à Amazônia, impedindo uma visualização mais real do que foi sua passagem pela região. Pela falta de informações, imagina-se o que seria um escritor de outro país falando de uma cidade amazônica no final da década de 1950. Na obra de Daniel Chiarenza ${ }^{4}$, o capítulo referente à chegada do ex-ministro a Belém chama-se "Vida, pasión y muerte en Belem do Pará" e contém toda espécie de martírio e provações na vida do "herói", só faltando mesmo a ressurreição. Nessa obra, Belém é descrita como "[...] este pueblito, perdido en la baja do Marajó [...] parecía sacado de una novela de Gabriel García Marquez: un pueblito triste con fantasmagóricas figuras que anunciaban el trágico futuro del doctor Carrillo."4. Diante disso, tentaremos colocar o Dr. Ramón Carrillo em uma Belém mais condizente com a realidade do período.

Não se diga, com isso, que sua vida na capital do Pará foi fácil. Carrillo assumiu seu trabalho em $1^{\circ}$ de novembro ${ }^{3}$. Consistia em viajar duas vezes por semana para a mina de ouro Aurizonia ${ }^{6}$, explorada pela Hanna Mining Company e situada há dois dias de viagem fluvial partindo de Belém ${ }^{13}$. O acesso ao local dava-se pelo avião da companhia, um biplano apelidado de "El mosquito", ou pelos típicos barcos amazônicos, com ganchos para armar rede. Carrillo, que tinha pavor de aviões, preferia viajar nos "popopô"*, o que significava um enorme sacrifício para um homem obeso, hipertenso e, o mais importante, não acostumado ao uso de redes, tendo caído dessas pelo menos uma vez durante a viagem ${ }^{4}$.

Sobre a Hanna Mining Company e sua mina, as referências são escassas. Todas as localizadas estão ligadas ao Dr. Ramón Carrillo. Parece, em um primeiro momento, que o que restou da memória institucional da empresa se deveu graças à vinda do ex-ministro. Nem a localização precisa do acampamento foi possível determinar, sendo mencionada como uma "[...] la travesía se hacía larga y peligrosa a través del Amazonas.". ${ }^{14}$ Deduz-se que esse local se situava em um território hoje pertencente ao estado do Amapá, o qual vivia, nas décadas de 1940 e 1950, os primeiros tempos da exploração de manganês, com participação da Hanna Coal \& Ore Corporation, subsidiária da Hanna Mining Company ${ }^{14}$.

Carrillo descreve a mina como um lugar onde os índios e caboclos nunca haviam visto um médico, e só dispondo de um banheiro público, que ele jocosamente explicava que "público" se referia ao fato do usuário não ter nenhuma privacidade, era apenas uma tábua com buracos ${ }^{6}$.

\section{UM NEUROCIRURGIÃO EMBAIXO DA ESCADA}

Procurando mais uma atividade, o médico, em uma tarde, foi solicitar trabalho no Hospital da Santa Casa de Misericórdia (Figura 2). É sua esposa, Susana Pomar, quem narra o diálogo entre Carrillo e um funcionário, que, dependendo da obra, às vezes é referido como o diretor do Hospital:

\footnotetext{
-¿Qué especialidad hace usted?

-Neurologia. Contestó Carrillo, sin aclarar quién era ni qué antecedentes tenía.

-No hay partida para el puesto.

-No me interessa cobrar um sueldo.

-Pero no tenemos lugar.

-Es que no necesito um despacho.
}

O lugar oferecido foi um canto debaixo de uma escada. E quando perguntado do que mais precisava, o médico argentino respondeu: "Una mesa y una silla, el lápiz lo pongo yo. ${ }^{14,6,13}$.

Aqui começam as questões que naturalmente só poderiam ser levantadas por quem conhece Belém. Familiarizando-se com a arquitetura da Santa Casa, é difícil conceber alguém atendendo embaixo de uma escada. É mais provável que o médico tenha conseguido um espaço em um dos porões daquele hospital, que eram utilizados como enfermarias, e talvez próximo às escadas de acesso aos mencionados setores. Conhecendo as descrições dos famosos "porões da Santa Casa" naquela década, esses deviam ser, de qualquer forma, acomodações bastante improvisadas na visão de um homem que havia escrito um volumoso tratado, chamado Teoria do Hospital, sobre organização, administração e arquitetura hospitalar ${ }^{3}$.

Os autores argentinos normalmente referem que, em Belém, a Neurologia, citada como existente por alguns escritores, é definida como muito incipiente, e a Neurocirurgia, uma utopia, e que a Santa Casa não dispunha de serviços especializados ${ }^{4,5,6}$.

Entretanto, a realidade não era bem essa. Em 


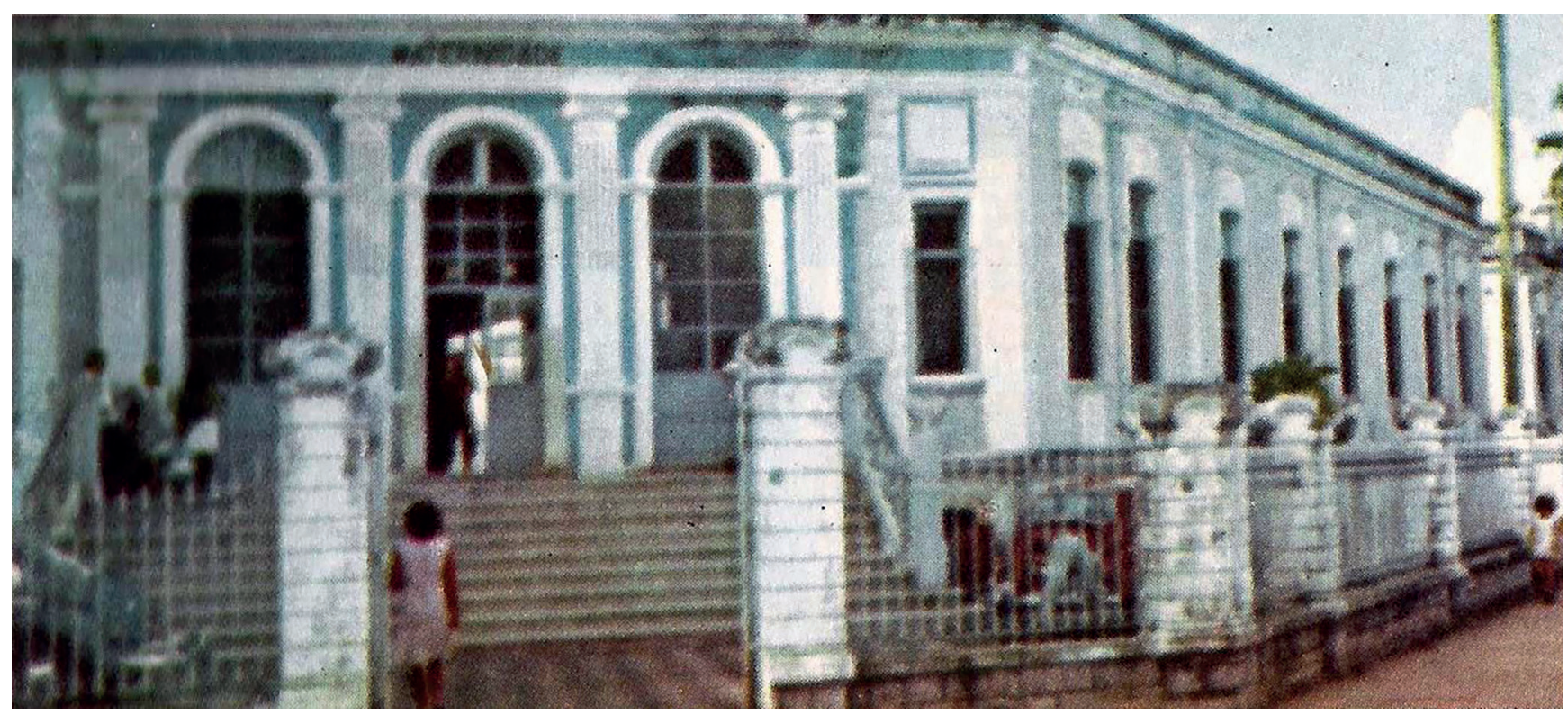

Fonte: Amazônia é Brasil. Comemoração do primeiro centenário da abertura dos portos da Amazônia. Belém: Vitória Régia Editora; [196-].

Figura 2 - Entrada principal do Hospital da Santa Casa de Misericórdia do Pará na década de 1960

Belém, o ensino da Neurologia já estava sendo praticado desde 1919, com a criação da Faculdade de Medicina e Cirurgia do Pará (Figura 3), estabelecimento que funcionava exatamente em frente à Santa Casa e que, nos anos de 1950, já contava com um professor especializado em Neurologia, o Dr. Pedro Nicolau dos Santos Rosado, com conhecimentos adquiridos por meio de cursos nos EUA, na Universidade de Columbia e em Harvard, e que, no ano de 1956, defendeu sua tese para a cátedra dessa disciplina, intitulada "Estudo dos distúrbios nervosos produzidos pelo uso da maconha"15.

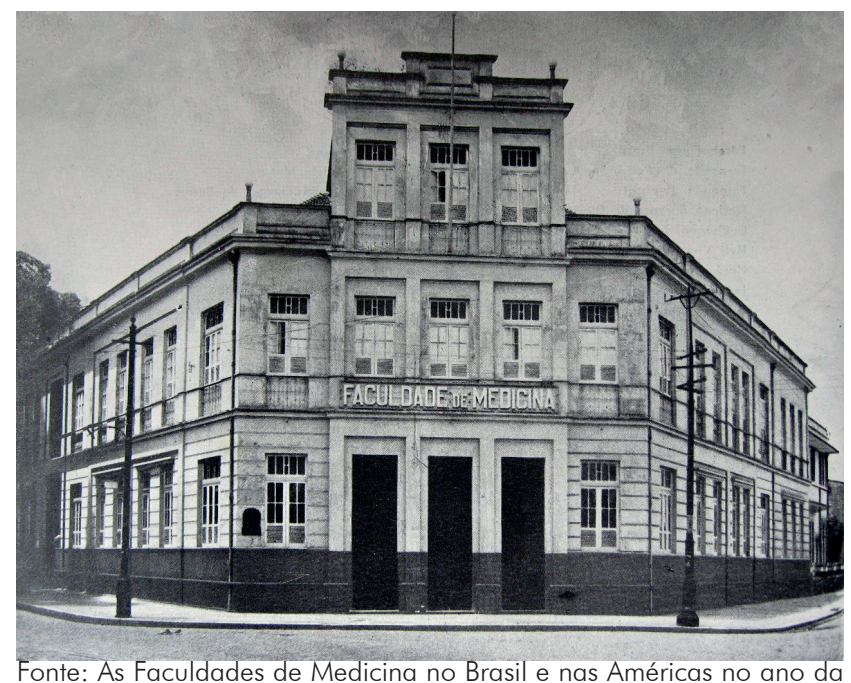
vitória. São Paulo: Laborterápica; 1945.

Figura 3 - Faculdade de Medicina e Cirurgia do Pará

- Hospital da Santa Casa já reservava a enfermaria São João para os casos neurológicos, onde o Prof. Pedro Rosado ministrava suas aulas práticas ${ }^{16}$. Formalmente, aquele espaço era considerado como sendo um "Serviço de Neurologia" do qual Rosado foi nomeado chefe em 1962 17. A Neurocirurgia, pela sua complexidade e falta de suporte pós-operatório, estava longe de ser uma rotina estabelecida, mas, no começo daquela década, o Pará já contava com um neurocirurgião formado, residindo em Belém, o Dr. Eloy Simões Bonna, que, em 1951, na Santa Casa, realizou a primeira cranioplastia e reposição da dura-máter e, entre 1950 e 1954, lecionou na Faculdade de Medicina, sob supervisão do Prof. Rosado ${ }^{18}$.

\section{CEME JORDY: O ÚLTIMO DISCÍPULO}

"Desde o primeiro momento iniciamos uma
relação que foi sempre, mistura de Mestre
e aluno e estreita amizade [...]"

Ceme Jordy ${ }^{13}$.

A história oficial segue sua narrativa, contando que "[...] em pouco tempo um jovem residente [...]", entretanto a Santa Casa, naquela época, ainda não tinha um programa de residência médica nos moldes do que entendemos hoje, mas sempre foi um ponto de partida para profissionais recém-formados galgarem seus primeiros degraus. E então um jovem médico passou a consultar o ex-ministro, que lhe dava atenção e the tirava dúvidas sobre casos mais difíceis que se apresentavam no hospital. Assim, aquele jovem passou a contestar médicos mais experientes nas discussões clínicas com muita segurança, causando grande assombro. $O$ segredo foi logo revelado. Seus conhecimentos vinham do médico argentino que atendia debaixo da escada ${ }^{4,6}$.

Os colegas brasileiros então the convidaram para reuniões científicas onde Carrillo respondeu a todas as perguntas, deixando os colegas fascinados com seus conhecimentos. Paralelamente, chegou a resposta de um telegrama enviado ao Rio de Janeiro, perguntando quem era "o Dr. Ramón Carrillo da Argentina?". Tudo então se esclareceu e o médico passou a dar aulas na Santa Casa, quando os ataques de dor de cabeça lhe permitiam, e a trabalhar no Hospital de Aeronáutica de Belém ${ }^{4,6}$. 
Mas retornemos ao jovem médico e vamos deixar que o próprio Carrillo o apresente em carta a sua irmã em 20 de março de 1956: "Yo estoy haciendo discípulos; ya tengo uno que se llama Ceme Ferreira Jordy, médico, que me ha asistido en mi enfermidad, y que tiene gran interés por mis ideas."6.

Ceme Jordy havia colado grau na última turma da Faculdade de Medicina e Cirurgia do Pará, que saiu em dezembro de 1955. Quando começamos a levantar dados mais concretos sobre Ramón Carrillo e chegamos ao nome de Jordy, descobrimos que - mesmo já havia falecido em São Paulo, no ano de 2008. Felizmente, o Dr. Ceme Jordy deixou um depoimento escrito sobre sua relação com o neurocirurgião exilado ${ }^{13}$ :

Foi Adib Nasser um empresário paraense, quem me apresentou ao Prof. Ramón Carrillo alguns dias após sua chegada a Belém. Um amigo de Adib também empresário encontrara Carrillo em Nova York e o trouxe com esposa e filhos [...]

Nas suas primeiras linhas, a versão do residente que acha um grande médico atendendo embaixo da escada como quem encontra um tesouro perdido, é posta em cheque. Independente de como o conheceu, Ceme afirma que ${ }^{13}$

[...] Carrillo estava exilado e na penúria. Para mim era como um anjo caído do céu. Eu estava me preparando para deixar Belém, desejava me complementar em neurologia fora do Brasil. A chegada de Ramón foi uma dádiva para mim.

Ceme, que antes de ser médico desejava ser filósofo, ficou fascinado com a cultura do ex-ministro, que se estendia muito além da Neurocirurgia, de maneira que estabeleceram uma grande amizade e conversavam, além de Medicina, sobre temas como psicanálise, filosofia e história da arte. Com tantas afinidades eletivas, iniciaram um ambulatório de atendimento a pacientes com doenças neurológicas na Santa $\mathrm{Casa}^{13}$.

O Prof. Ramón não podia clinicar sem ter a sua condição profissional regularizada no Brasil, mas conseguíamos atender em meu consultório particular, onde examinávamos juntos meus pacientes e ele podia assim receber os proventos das consultas.

Nossos compromissos eram três: nas manhãs, íamos ao ambulatório da Santa Casa, umas três vezes por semana. [...] de volta a casa, à hora do almoço, aproveitávamos esses nossos melhores momentos de boa conversa. Parávamos sempre em um bar: "Vamos parar um pouco aqui Ceme tenho que preparar-me para suportar a dieta que me espera em casa". Tomava um copo de Vermouth com uma cereja ou azeitona dentro e dizia que a fruta extraia - álcool da bebida, mas após sorver do copo, comia a fruta. De tarde, em geral após as 16 horas, atendíamos clientes particulares no meu consultório, e no restante do tempo disponível conversávamos sobre assuntos culturais.

Não tendo sua condição profissional regularizada no Brasil, essa foi a maneira que Carrillo utilizou para obter alguma remuneração, trabalhando em parceria com Ceme Jordy. Em nossas pesquisas, achamos depoimentos de pessoas que tiveram seus parentes atendidos por ambos $^{19}$ :
[...] o dr. Ramon Carrillo foi conduzido pelo dr. Ceme Jordy ao quarto em que meu sogro estava internado, após sofrer A.V.C., no Hospital da Beneficiente Portuguesa de Belém. Foram dias de muita aflição e tristeza, nunca mais tivemos contato com dr. Ramon - que durante a visita se mostrou atencioso e discreto. Isso ocorreu nos primeiros dias de setembro, em 1956

Ceme Ferreira Jordy depois se mudou para São Paulo, especializando-se em Neurologia na Escola Paulista de Medicina, tornando-se um renomado professor daquela Instituição, defendendo sua tese de livre docência intitulada "Um estudo clínico da motricidade reflexa em 100 pacientes de lepra" em $1967^{20}$ e publicando diversos outros trabalhos na área ao longo de sua existência.

\section{GRANDES SILÊNCIOS}

"Tornar-se senhor da memória e do esquecimento é uma das grandes preocupações das classes, dos grupos, dos indivíduos que dominaram e dominam as sociedades históricas. Os esquecimentos e os silêncios da história são reveladores desses mecanismos de manipulação da memória coletiva."

Le Goff'21.

Como já dito, após ser "descoberto" pelos colegas paraenses, além de continuar seu trabalho na Santa Casa, Carrillo foi convidado para colaborar também com o Hospital de Aeronáutica de Belém (Figura 4), assumindo questões ligadas à Neurologia e administração hospitalar ${ }^{4}$. A memória coletiva de suas ações nesses estabelecimentos hoje é muito esparsa. Sobre a Santa Casa, há o depoimento já citado de Ceme Jordy. No Hospital de Aeronáutica ele é lembrado oficialmente como "[...] um grande colaborador, palestrante e conferencista" tendo vasto conhecimento de uma especialidade que era rara na época ${ }^{22}$. Pesquisando nesse hospital, ainda coletamos curto depoimento de um cabo reformado que dizia lembrar-se da figura do Dr. Carrillo como um homem grande, simpático, estrangeiro, de fala enrolada, sempre disposto a atender quem o solicitasse.

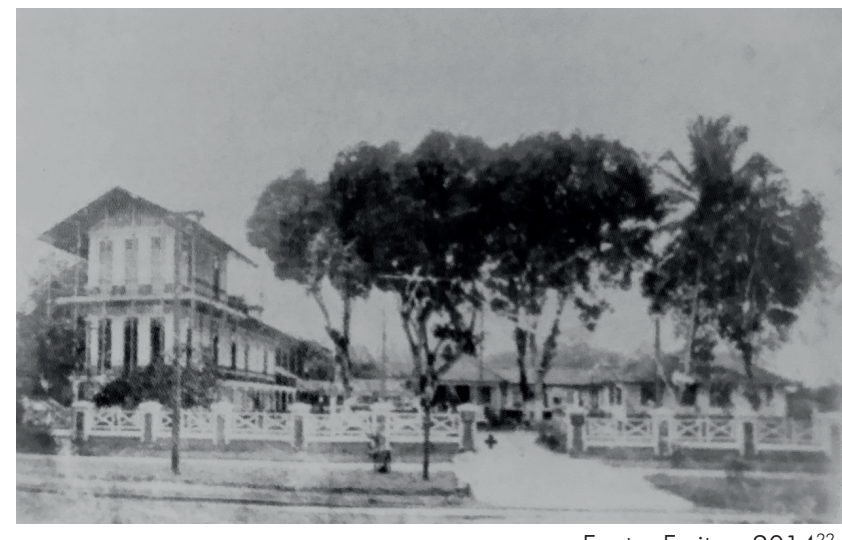

Figura 4 - Hospital de Aeronáutica de Belém nos anos de 1940

A questão fica interessante quando notamos que o Hospital de Aeronáutica, na época, estava localizado em uma região fora dos limites urbanos de Belém. É 
em uma instituição militar, distante do centro da cidade, que o ex-ministro, um foragido político, consegue maior espaço. Entretanto, havia uma Faculdade de Medicina em frente à Santa Casa, e tudo o que achamos é um silêncio enorme quando buscamos a relação entre Ramón Carrillo e a Faculdade de Medicina e Cirurgia do Pará. É um contrassenso que ele tenha se aproximado mais de um hospital longínquo, que tinha todos os motivos para não lhe dar abrigo, do que de uma instituição de ensino médico.

Nas cartas que Carrillo enviou do exílio para seus familiares e amigos, apenas uma pequena parte já foi publicada, ainda que parcialmente. Em uma delas, o médico passa sua visão da Faculdade de Medicina como uma instituição muito pequena que não chegava a 200 alunos no totalb.

Uma das justificativas para a Faculdade de Medicina e Cirurgia do Pará não ter aproveitado o cabedal de conhecimentos de Ramón Carrillo certamente deveu-se à sua condição de estrangeiro, o que o impedia de exercer legalmente a profissão. Ele deveria ter seu diploma revalidado para tal. Isso implicaria muitas questões burocráticas, demandando um tempo que, talvez, Carrillo não estivesse disposto a perder. Ou não poderia mais perder, considerando o agravamento da sua condição de saúde.

Outra hipótese a ser considerada pode ter sido o "incômodo" que, talvez tenha causado a presença de um neurocirurgião, com vasto conhecimento científico e cultural, abalando as verdades absolutas de muitos catedráticos da Faculdade de Medicina e Cirurgia do Pará. Não esquecendo, também, a questão política: se ele era persona non grata para o governo argentino, por que desagradar aos hermanos?!

Por outro lado, tanto Jordy ${ }^{13}$ como o próprio Carrillo, em cartas $^{6}$, referem que esse último proferiu conferências na Faculdade de Medicina e Cirurgia do Pará e estava inclusive estudando para disputar a cátedra de Patologia Geral, apoiado pelos estudantes e por alguns professores. É possível que a Faculdade não tenha registrado essas palestras ou mesmo assumido Carrillo como professor convidado, como dito acima, pela sua condição de exilado político, considerado criminoso em seu país de origem naquele momento.

$\mathrm{Na}$ contramão, outras instituições fora do Pará não apresentaram esses pudores, e Carrillo foi convidado para reger uma cátedra de Filosofia na Universidade de Porto Alegre, no estado do Rio Grande do Sul, fato que teria não se concretizado apenas por falta de dinheiro para a viagem ${ }^{6}$.

Independente das razões que ainda possam ser descobertas, permanece a questão de que Ramón Carrillo não se ligou à Faculdade de Medicina local da forma como seria de se esperar para um nome da sua projeção. mesmo se pode questionar em relação às autoridades de saúde no Pará. Sendo Carrillo possuidor de um vasto currículo, abrangendo tanto - mais avançado, como a Neurocirurgia, quanto o mais que sempre necessário, o sanitarismo, por que não foi aproveitado como uma espécie de consultor? Impedimentos legais? Ciúmes profissionais?

\section{OUTRAS ATIVIDADES MÉDICAS E VIDA SOCIAL EM BELÉM}

"[...] se llega a la conclusión de que aún en el culo del mundo- y quizás especialmente allí- hay gente buena, dispuesta a la solidaridad humana, sin interés de ninguna classe."

Ramón Carrillo sobre Belém, em carta para a sua mãe

Como viveu Ramón Carrillo em Belém? Qual a sua rotina de trabalho, além da Santa Casa e do Hospital de Aeronáutica? E de vida?

Dos textos produzidos pela imprensa de Belém, por ocasião de sua morte, podemos extrair algumas informações. Seu endereço foi mencionado como sendo à Travessa Benjamin Constant, sem maiores detalhes $^{23, \dagger}$ (Figura 5).

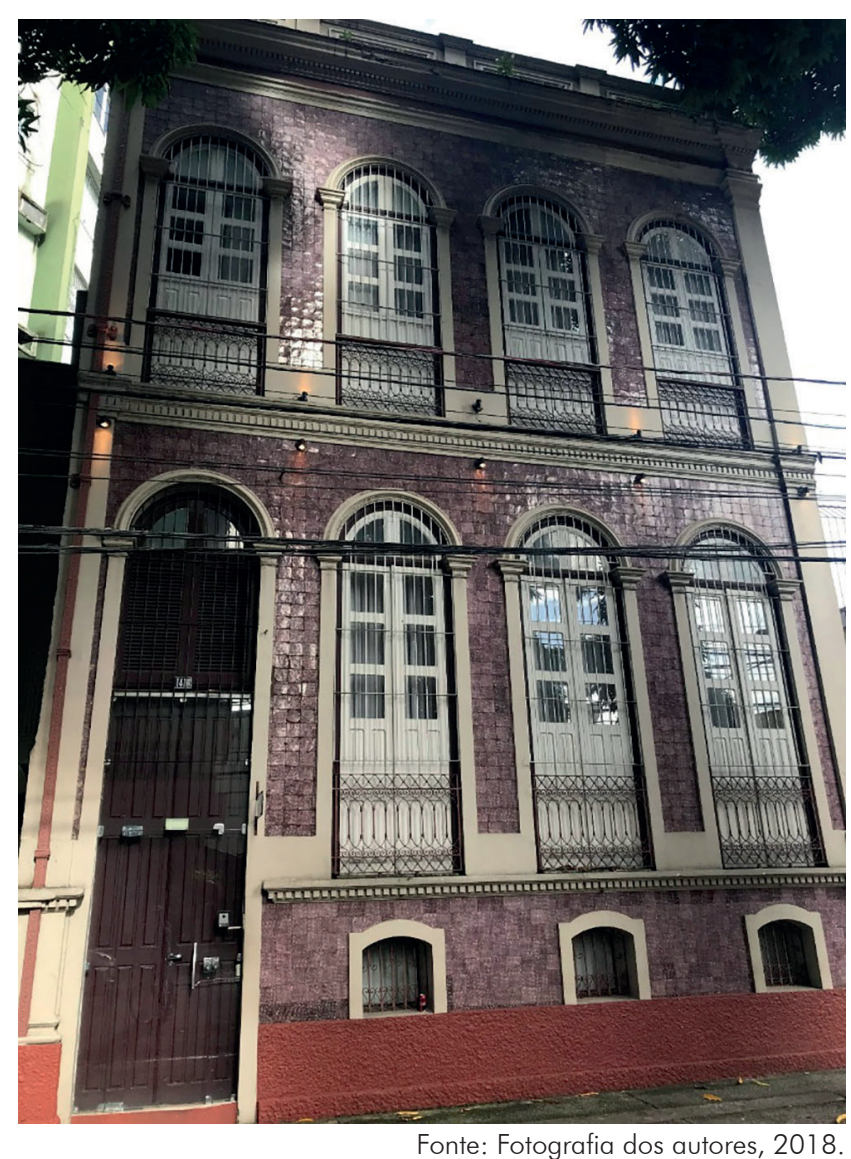

Figura 5 - Casa onde morou a família Carrillo em Belém 
Carrillo é descrito como alguém "[...] insulado na modéstia natural [...]", "[...] confundindo-se, no seu novo e adverso dia a dia, com os mais humildes lutadores da vida, passando e repassando, anonimamente, pelas nossas ruas $[\ldots] "$, e prossegue o texto ${ }^{24}$ :

Quem o visse espremido num ônibus de subúrbio, jamais poderia imaginar que ali estava um ex-ministro de Estado e, mais do que ministro, um luminar da medicina especializada. Sua fisionomia e sua resignação encobriam a amargura que, de certo, lhe minava o íntimo.

Um registro da atividade científica de Ramón Carrillo em Belém: em outubro de 1956, cinco casos suspeitos de poliomielite foram notificados à Secretaria de Saúde. As autoridades sanitárias promoveram uma reunião para debater o assunto e adotar as medidas de combate necessárias. Entre os presentes, Eleyson Cardoso, delegado federal de Saúde; Ottis Causey, pela Fundação Rockfeller, de passagem por Belém; Joaquim Travassos, virologista do Instituto Oswaldo Cruz; Laurênio Soares e Simões, do Serviço Especial de Saúde Pública; Henry Kayath, secretário de saúde; e Ramón Carrillo, citado como "[...] ex-ministro de Saúde Pública da Argentina, presentemente residindo em Belém [...]"25.

Sobre a participação de Ramón Carrillo na reunião, transcrevemos ${ }^{25}$ :

\section{CONTRIBUIÇÃO LOUVÁVEL}

$\bigcirc$ dr. Ramón Carrillo deu grande contribuição pessoal à reunião, oferecendo uma série de idéias para o combate à poliomielite, desde a fase investigadora até o último estágio de uma campanha de extermínio da doença. $\bigcirc$ dr. Carrillo, bastante conhecido em nossos meios médicos, especialista em neurologia, é, no entanto, um profundo conhecedor daquele problema de saúde pública, pois no governo Perón dirigiu o Ministério da Saúde Pública na nação platina. Como se sabe, a Argentina é, talvez, o país sul-americano mais sacrificado pela paralisia infantil, com autênticas epidemias periódicas que causam um enorme número de vítimas. Ainda há poucos meses, a poliomielite levou os govêrnos das vizinhas repúblicas a fechar suas fronteiras com a Argentina. Por isso, o dr. Carrillo contribuiu com uma série de sugestões para o melhor traçado de uma campanha-base que servirá para ser adotada em qualquer época, em nossa capital, com cujos problemas sanitários iá se familiarizou aquele médico argentino. Expendendo suas opiniões, o dr. Carrillo foi ouvido durante muito tempo pelos presentes, sendo depois cumprimentado pelo governador, que agradeceu o esforço e o espírito de compreensão e de colaboração do sanitarista portenho.

Carrillo escreve para a família e relata esse fato, afirmando ter diagnosticado os cinco casos, contrariando os diagnósticos dos médicos locais que afirmavam que pólio não existia na região ${ }^{6}$. Nas semanas seguintes, para alívio geral, apenas um caso de pólio foi confirmado em fase de contágio já superada ${ }^{26}$.
Da notícia do jornal Província do Pará, depreende-se duas coisas: Carrillo "existia" para as autoridades de saúde de Belém e era também conhecido da imprensa, merecendo inclusive nota social pelo seu aniversário em março de 1956²7:

\section{Prof. RAMON CARRILLO \\ Transcorre hoje o aniversário natalício do ilustre professor doutor Ramon Carrillo, autor de um grande numero de trabalhos sobre cirurgia nervosa e neuro-psiquiátrica. \\ nataliciante é um dos mais destacados nomes dos meios científicos da República Argentina tendo mesmo ocupado a Pasta da Saúde Pública no Governo Peron. Além disso, é professor catedrático da Universidade de Buenos Aires e membro de varias Academias internacionais de Medicina.}

Carrillo de fato teve uma vida social local, buscando, de algum modo, integrar-se à cidade, referindo, em cartas, idas a bailes de carnaval (onde se entusiasmou a ponto de prometer tentar compor uma marchinha), visita a um terreiro de umbanda e ter assistido ao Círio de Nazaré, onde os romeiros "[...] venidos de todas partes celebran la virgen con fervor, alegría y fiesta y hoy, muchos borrachos"6.

Sobre as amizades médicas, além do pupilo Ceme Jordy, há menção de privar da amizade do médico Silvio Bentes", "renomado clínico conterrâneo", e de ter morrido "cercado dos desvelos de amigos e colegas paraenses" 24 . Contraditoriamente, ora Carrillo queixava-se de isolamento e abandono em Belém, sem conseguir exercer oficialmente sua profissão, ora ressaltava a bondade, a cordialidade e a hospitalidade do paraense $^{6}$.

Sua vida como exilado foi assim, cheia de altos e baixos. Belém reservou ao médico pelo menos duas grandes frustrações. A maior delas ocorreu no Hospital Juliano Moreira, então o hospício da Cidade, onde, com o apoio do diretor da instituição, o Dr. Durvalino Braga, realizou uma lobotomia frontal bilateral em um paciente. Dada a baixa infraestrutura do local e a inexperiência dos anestesistas em Neurocirurgia, o paciente veio a falecer vítima de infecção hospitalar no pós-operatório imediato. Ceme Jordy, seu fiel escudeiro, assim recorda ${ }^{13}$ :

Este fato provocou um desconforto no meio médico, especialmente entre os cirurgiões de Belém, que agora tinham o que antes não tinham para também dizer "ele também tem seus erros", "ele também tem seus fracassos". Isso era injusto, não houvera erros técnicos, mas insuficiência de condições hospitalares para tal procedimento. [...] Mas Ramón ele mesmo foi quem sofreu. Ficou muito abalado, contava-me repetidamente as causa do fracasso, cuja responsabilidade não era sua.

Outra frustração foi não conseguir realizar um curso de Filosofia que planejou, para ser ministrado na Faculdade de Direito com o título "Teoria geral

‡ Lembrado como um médico de raciocínio clínico muito apurado, porém com gênio forte, muitas vezes não compreendido pelos colegas, ainda que estimado e respeitado pelos pacientes. Sempre com estudantes ao redor, ensinava espontaneamente nas enfermarias da Santa Casa com muita desenvoltura, mesmo sem enveredar pela carreira de professor. Faleceu em $1992^{28}$. 
do homem", que posteriormente daria origem a um volumoso livro, o que Carrillo considerava vir a ser sua obra mais importante, definitiva e consagratória. $O$ médico passou os meses de maio, junho e julho entregue com grande entusiasmo a esse trabalho, escrevendo quatro páginas por dia ${ }^{6}$.

○ curso seria organizado pela União Acadêmica Paraense (UAP) e acabou não sendo realizado. No relatório da Instituição ${ }^{29}$, podemos ler que:

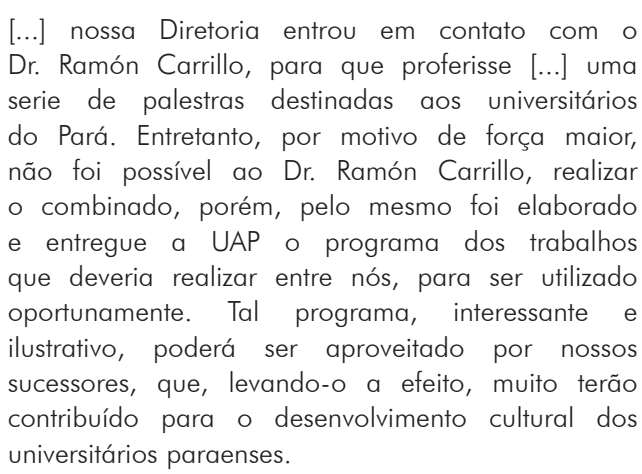

[...] nossa Diretoria entrou em contato com o Dr. Ramón Carrillo, para que proferisse [...] uma serie de palestras destinadas aos universitários do Pará. Entretanto, por motivo de força maior, não foi possível ao Dr. Ramón Carrillo, realizar - combinado, porém, pelo mesmo foi elaborado e entregue a UAP o programa dos trabalhos que deveria realizar entre nós, para ser utilizado oportunamente. Tal programa, interessante e ilustrativo, poderá ser aproveitado por nossos sucessores, que, levando-o a efeito, muito terão contribuído para o desenvolvimento cultural dos universitários paraenses.

Os alegados motivos de força maior permanecem desconhecidos, porém é possível especular que estavam relacionados à saúde de Carrillo, que se deteriorava, fazendo-o conviver com crises de cefaleia cada vez mais frequentes, decorrentes de sua hipertensão maligna. $\bigcirc$ programa do curso chegou a ser impresso pelo Governo do Estado do Pará, provando o prestígio local que o sanitarista, em poucos meses, tinha galgado§, oferecendo uma pálida ideia do que seria a obra escrita.

\section{A MORTE E SEUS DESDOBRAMENTOS}

"Durma aqui o expatriado o seu último sono."

Com a saúde precária e agravando progressivamente, aliado às adversas condições de sobrevivência, pouco mais de um ano após sua chegada à capital paraense, Carrillo sofreu um acidente vascular cerebral, sendo internado no Hospital de Aeronáutica de Belém, onde veio a falecer às 7h30 do dia 20 de dezembro de 195631. Do período de quase 30 dias de internação, sobreviveram apenas duas lacônicas anotações nos boletins internos do hospital: a "baixa no hospital", em 29 de novembro de 1956, e a sua "alta por falecimento" em 20 de dezembro de 1956, sempre sob responsabilidade do Major Médico José Alfredo Guilherme da Silva ${ }^{32,33}$.

Sobre o período internado, Alzugaray ${ }^{5}$ refere que se estabeleceu um contato radioamador entre neurologistas argentinos e os médicos que atendiam Carrillo em Belém. Essas comunicações aconteciam cerca de duas vezes por dia e de forma clandestina, já que, para a Argentina de 1956, querer salvar a vida de Ramón Carrillo era um delito. Havendo necessidade de medicações não disponíveis no Pará e com a família sem recursos para custeá-los, essas foram compradas no Rio de Janeiro por amigos de Ramón, o jornalista Emilio Perina e o Dr. Barros Hurtado, e enviados em aviões da Força Aérea Brasileira. Tal auxílio chegou a gerar protestos do embaixador da Argentina no Brasil, Felipe Espil, argumentando que o governo brasileiro estava promovendo cuidados especiais, por via oficial, a um foragido da justiçá ${ }^{6}$.

Depois de morto, Carrillo teve seu corpo embalsamado para ser transportado para a Argentina. O serviço foi realizado pelo catedrático de anatomia da Faculdade de Medicina e Cirurgia do Pará, Dr. Ruy Romano da Silva Romariz, que utilizou, pela primeira vez na região, o chamado "Método Espanhol", que poucos anos depois seria repetido no preparo do cadáver do Governador Magalhães Barata ${ }^{34}$. No centro do anfiteatro da Santa Casa, o cadáver foi preparado diante de um número grande de alunos que a tudo assistiram em respeitoso silêncio ${ }^{5}$.

Entretanto, sua última viagem para a Argentina não se deu de imediato. Segundo os jornais, a Embaixada Argentina no Brasil enviou um telegrama à "[...] família paraense, com a qual residia o ilustre médico, em Belém [...]", informando que o governo argentino não permitia o sepultamento de Ramón Carrillo em sua pátria, pelo fato de ele ser peronista e ter ocupado cargos de destaque na administração de Perón ${ }^{35}$. Em outro jornal, a informação diz que consultada sua família na Argentina, "[...] esta resolve determinar o sepultamento em Belém [... $]^{1136}$. A mesma nota afirma ter circulado notícias em Belém de que o governo argentino havia negado permissão para o sepultamento em solo argentino, mas, segundo a reportagem, nada havia de oficial sobre tal decisão.

Registre-se que a Universidade do Rio Grande do Sul cogitou transferir os restos mortais de Carrillo para Porto Alegre, "[...] até que sua pátria os queira, enfim, receber $[. . .]^{\prime \prime}$, ele que tinha o título de Doutor Honoris Causa da universidade gaúcha e que fora convidado para ali "[...] ensinar e pesquisar [...]", o que não pôde fazê-lo, colhido que fora pela morte ${ }^{37}$.

Independente das questões políticas e dos complicados e dispendiosos trâmites burocráticos para o traslado do cadáver, a família de Carrillo não viu problema em deixá-lo em Belém. Santiago, seu irmão, entendeu que a cidade the deu asilo e the recebeu amistosamente, referindo que muitas pessoas o admiravam e o respeitavam de forma sincera, pois pouco ou nada poderiam esperar de um exilado. $\bigcirc$ próprio Carrillo se sentia bem em Belém, pois recusou convites para ir para outros lugares, como Panamá e Uruguaib.

Somente em 1972, por requerimento do Consulado da Argentina no estado de Pernambuco, o corpo de Carrillo foi exumado e transportado para a Argentina, ficando antes em câmara ardente na Aeronáutica (no hospital?). Segundo a notícia, o corpo ainda se

$\S \bigcirc$ programa pode ser acessado pelo site http://electroneubio.secyt.gov.ar/Ramon_Carrillo_Teoria_Geral_do_Homem.htm. 
encontrava em perfeito estado, constatado pelo autor do procedimento inicial, o Prof. Dr. Ruy Romariz ${ }^{38}$.

\section{CONCLUSÃO}

"Ramón Carrillo, eminente médico, ex-ministro da Saúde Pública de nosso governo, acaba de morrer na última miséria em Belém do Pará, onde trabalhava duramente para manter sua esposa e filhos"

Juan Perón ${ }^{39}$.

Por meio deste estudo, buscamos mostrar alguns aspectos da vida de Ramón Carrillo na cidade de Belém. Ao contrário do senso comum, o historiador nunca resgata o passado. A maior parte dos acontecimentos se perde no tempo; no máximo, a pesquisa consegue informações fragmentadas que serão agrupadas em uma tentativa de mostrar um panorama do passado. Uma janela embaçada ou uma foto incompleta seriam boas metáforas.

No caso deste personagem, por mais que não se queira cair na armadilha de uma biografia literária, cheia de façanhas arrojadas, os aspectos da sua vida meteórica tornam isso quase inevitável. De herói nacional a vilão foragido. De médico aos 24 anos de idade, professor catedrático aos 36, ministro da saúde aos 37 e exilado político ao 49. Homem cosmopolita que conheceu os grandes centros científicos do mundo e acabou seus dias em uma capital provinciana encravada na Amazônia brasileira (Figura 6). Se esse romantismo acaba sendo inevitável, em uma tentativa de recompor a existência de Carrillo, melhor encerrar com a visão de seu último aluno Ceme Jordy ${ }^{13}$ :

Pobre Ramón, um gigante empobrecido, que viveu a desventura de trocar a grande paixão de sua vida, a Ciência e o Ensino, pelo afã de entregar-se a Pátria. A ela se entregou, talvez por caminhos forçados, com os quais não concordava e foi, por ela, enfim, abandonado. Muitas vezes penso comigo, que Ramón viveu a infortunada história de um anti-herói.

\section{AGRADECIMENTOS}

Ao Dr. Mário Crocco, da Fundação Ramón Carrillo na Argentina, com quem trocamos correspondência eletrônica entre julho e agosto de 2015, por ter nos fornecido orientações de grande valia e incentivo para a elaboração deste trabalho.

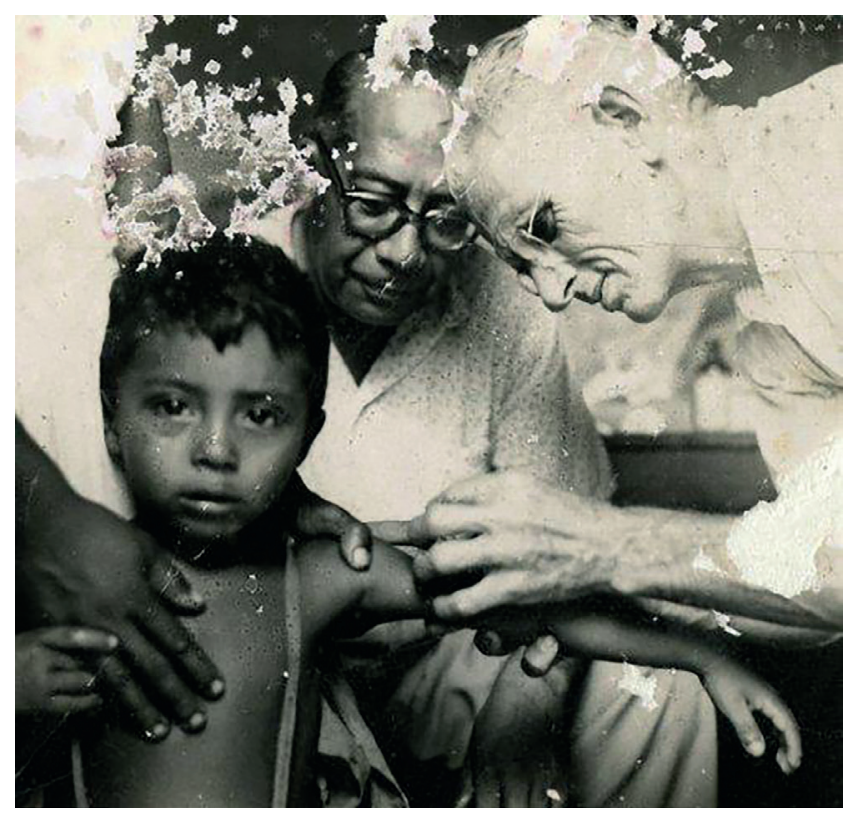

Fonte: Ross P. The construction of the Public Health System in Argentina 1943-1955. Electroneurobiología, 2007;15(5):107-78.

Figura 6 - Ramón Carrillo (ao centro), no exílio, ajudando uma campanha de vacinação na mina onde arrumou emprego

Ao Capitão Médico da Força Aérea Brasileira Eduardo Fernandes do Carmo, que entusiasmado com esta pesquisa, franqueou-nos acesso ao Hospital de Aeronáutica e aos Boletins Internos da Instituição em setembro de 2015.

Ao Grupo Alubar, na figura do senhor Tiago Chaves, analista de comunicação da empresa, que nos presenteou com um exemplar do livro "Dr. Ramón Carrillo: de Santiago del Estero a Belém do Pará", obra já fora de catálogo, a qual não tínhamos acesso e que representava uma fonte essencial para a realização deste artigo.

\section{CONFLITOS DE INTERESSE}

Os autores declaram não ter havido conflitos de interesse.

\section{CONTRIBUIÇÃO DOS AUTORES}

Todos os autores contribuíram com a idealização do estudo, a análise e a interpretação dos dados e com a redação do manuscrito, aprovando a versão final publicada. Declaram-se responsáveis pelo conteúdo integral do artigo, garantindo sua precisão e integridade.

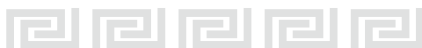

\section{REFERÊNCIAS}

1 Pinto I. Ismaelino (domingo): histórico. $\bigcirc$ Liberal. Belém, 2006 dez 10.

2 Bloch M. Apologia da história ou o ofício de historiador. Rio de Janeiro: Zahar; 2001. 159 p.

3 Carrillo R. Teoría del hospital. Buenos Aires: Ediciones Biblioteca Nacional; 2012.
4 Chiarenza D. El olvidado de Belem: vida y obra de Ramón Carrillo. Buenos Aires: Adrifer Libros; 2005.

5 Alzugaray RA. Ramón Carrillo: el fundador del sanitarismo nacional. Buenos Aires: Colihue; 2008. (Serie protagonistas).

6 Carrillo A. Ramón Carrillo: el hombre, el médico, el sanitarista. Buenos Aires: A. Carrillo; 2006. 
7 Matera RF. In memoriam: Prof. Ramón Carrillo. Arq Neuro-Psiquiatr. 1958 mar;16(1):77-82.

8 Síntese internacional. Diario de Noticias. Rio de Janeiro, 1956 out $24: 1$.

9 Barros R. Poblar y purificar: el otro Ramón Carrillo. La Nacion. Buenos Aires, 2007 ago 26:4.

10 Bourdieu P. A ilusão biográfica. In: Ferreira MM, Amado J, organizadores. Usos e abusos da história oral. 8. ed. Rio de Janeiro: FGV; 2006.

11 Cueto M, Palmer S. Medicina e saúde pública na América Latina: uma história. Rio de Janeiro: Fiocruz; 2016.

12 Veyne P. Como se escreve a história. 3. ed. Brasília: UnB; 1992. 198 p.

13 Borio PM, coordenador. Dr. Ramón Carrillo: de Santiago del Estero a Belém do Pará. Buenos Aires: El autor; 2006. 109 p.

14 Monteiro MA. A ICOMI no Amapá: meio século de exploração mineral. Novos Cadernos NAEA. 2003 dez;6(2): $113-68$.

15 Vultos da medicina paraense. Jornal do CREMEPA. Belém, 1984 jan-mar; 1:6.

16 Oliveira A. A pedra verde. Belém: Falangola; 1986.

17 Santa Casa de Misericórdia do Pará. Portaria $n^{\circ}$ 29/1962 CCL, de 13 de agosto de 1962. Nomeia Pedro Nicolau dos Santos Rosado para exercer as funções de Chefe da Clínica Neurológica. 1 folha datilografada.

18 Bonna MK. Eloy Simões Bonna 1922-1980. Para-Medico. 2001 set-out;8(1). Edição histórica.

19 Seligmann, Edith. Ramón Carrillo [Internet]. Mensagem para: José Maria de Castro Abreu Jr. 2015 set 17 [citado 2018 jul 25]. [1 parágrafo].

20 Jordy CF. Um estudo clínico da motricidade reflexa em 100 pacientes de lepra [tese]. São Paulo (SP): Escola Paulista de Medicina; 1967. 55 p.

21 Le Goff J. História e memória. Campinas: Unicamp; 1992.

22 Freitas TRD. Hospital de Aeronáutica de Belém: resgate de uma história. Belém: Cromos; 2014.
23 Faleceu o ministro de Saúde de Perón. Provincia do Para. Belém, 1956 dez 21:10.

24 Melo A. A morte de um exilado. Folha do Norte. Belém, 1956 dez 22:2.

25 Cinco casos de poliomielite notificados à Saúde. Provincia do Para. Belém, 1956 out 9:4, 9.

26 Poliomielite confirmado apenas um dos seis casos comunicados. Provincia do Para. Belém, 1956 out 14:22.

27 Professor Ramón Carrillo. Provincia do Para. Belém, 1956 mar 7:5.

28 Meira C. O Sylvio Bentes partiu. $\bigcirc$ Liberal. Belém, 1992 out 28.

29 União Acadêmica Paraense. Relatório da Diretoria. Gestão 1955-1956. Apresentado ao $30^{\circ}$ Congresso Estadual dos Estudantes. Belém, 1956 set. 49 p. Mimeografado.

30 Durma aqui o expatriado o seu último sono. Folha Vespertina. Belém, 1956 dez 22:1.

31 Registro fúnebre. Folha do Norte. Belém, $1956 \mathrm{dez}$ $21: 6$.

32 Ministério da Aeronáutica (BR). $1^{a}$ Zona Aérea. Boletim Interno do Hospital de Aeronáutica de Belém. Belém, 1956 nov 30;251. Item 12.

33 Ministério da Aeronáutica (BR). $1^{a}$ Zona Aérea. Boletim Interno do Hospital de Aeronáutica de Belém. Belém, 1956 dez $21 ; 269$. Item 7.

34 Rocque C. Magalhães Barata: o homem, a lenda, o político. Vol. 2. Belém: Secult; 2006.

35 Embalsamado o corpo do dr. Ramón Carrillo. Folha do Norte. Belém, 1956 dez 22:10.

36 Sepultado em Belém o dr. Ramón Carrillo. Provincia do Para. Belém, 1956 dez 22:10.

37 Paglioli E. Ramon Carrillo, um cadáver exilado. Diario de Noticias. Porto Alegre, 1957 jan 1:4.

38 Exumado o corpo do ex-ministro. Folha do Norte. Belém, 1972 dez 2:1, 4.

39 Perón J. "O pão duro e amargo do exílio". Mundo llustrado. Rio de Janeiro, 1957 abr 3;14:47. 